\title{
Proteínas do plasma seminal de caprinos relacionadas com o índice pluviométrico e a qualidade do sêmen
}

\author{
Proteins of goat seminal plasma related with precipitation index and semen quality
}

\author{
Andreia Fernandes de Souza ${ }^{{ }^{*}}$ Maria da Conceição Gomes LeitãoII André Mariano Batista ${ }^{\mathrm{I}}$ \\ Ana Lúcia Figueiredo Porto ${ }^{I}$ José Luiz de Lima Filho ${ }^{I I}$ Maria Madalena Pessoa Guerra ${ }^{I}$
}

\section{RESUMO}

\begin{abstract}
O objetivo deste estudo foi identificar as proteínas do plasma seminal de caprinos da raça Alpina Americana criados na região Nordeste do Brasil que estão relacionadas ao índice pluviométrico e à qualidade do sêmen. O sêmen foi obtido pelo método de vagina artificial a partir de três reprodutores e foi avaliado quanto aos parâmetros macroscópicos e microscópicos. O perfil de proteínas do plasma seminal foi realizado por eletroforese bidimensional. Os parâmetros volume do sêmen, integridade do acrossoma e proteínas totais evidenciaram diferença significativa $(P<0,05)$ entre os períodos de alto $\left(1,7 \mathrm{~mL}, 90,3 \%\right.$ e $372 \mu \mathrm{g} \mathrm{mL} \mathrm{m}^{-1}$, respectivamente) e baixo $\left(1,2 \mathrm{~mL}, 80,3 \%\right.$ e $494 \mu \mathrm{g} \mathrm{mL} \mathrm{L}^{-1}$, respectivamente) índice pluviométrico. Foram detectados, nos períodos de alto e baixo índice pluviométrico, 47 e 49 spots de proteínas com massa molecular relativa de 4 a $106 \mathrm{kDa}$ e de 15 a 97kDa e ponto isoelétrico de 3,00 a 8,96 e de 4,48 a 9,83, respectivamente. Apenas no período de alto índice pluviométrico foram observados os grupo de proteínas de $13 k D a$ e $45 k D a$. Conclui-se que o sêmen de caprinos da raça Alpina Americana criados na região Nordeste do Brasil apresenta-se com melhor qualidade quando colhido no período de alto índice pluviométrico, o que pode ser atribuído à presença das proteínas de $13 \mathrm{kDa}$ e $45 \mathrm{kDa}$.
\end{abstract}

Palavras-chave: Capra hircus, chuvas, características seminais.

\section{ABSTRACT}

The aim of this study was to identify proteins in seminal plasma of goats raised in the Northeast of Brazil related with precipitation index and semen quality. Semen was obtained from three bucks and evaluated to the microscopic and macroscopic parameters. The profile of seminal plasma proteins was performed by analysis of two-dimensional electrophoresis. Volume, acrosome integrity and total proteins had significant difference $(P<0.05)$ between the periods of high $(1.7 \mathrm{~mL}, 90.3 \%$ and $372 \mathrm{~g} \mathrm{~mL}^{-1}$, respectively) and low $(1.2 \mathrm{~mL}, 80.3 \%$ and $494 \mu \mathrm{g}$ $m L^{-1}$, respectively) precipitation index. It was detected during high and low precipitation index, 47 and 49 spots of proteins with molecular weight of 4 to $106 \mathrm{kDa}$ and 15 to $97 \mathrm{kDa}$, and isoelectric point of 3.00 to 8.96 , and 4.48 to 9.83, respectively. Only in the period of high precipitation index were observed groups of proteins with $13 \mathrm{kDa}$ and $45 \mathrm{kDa}$. It can be concluded that semen of Alpine American goats raised in the Northeast of Brazil has best quality when obtained in the period of high precipitation index, which can be attributed to the presence of protein with $13 \mathrm{kDa}$ and $45 \mathrm{kDa}$.

Key words: Capra hircus, rain, seminal characteristics.

\section{INTRODUÇÃO}

Nas regiões tropicais e subtropicais, os caprinos se reproduzem em todas as épocas do ano, porém sofrem influência de fatores ambientais, tais como alimentação e temperatura (NUNES, 1988). O estresse provocado por temperaturas ambientais elevadas, além de interferir nos parâmetros fisiológicos (temperatura retal e freqüência respiratória), afeta o desempenho reprodutivo dos animais via eixo hipotálamo-pituitária-gônada (RIVER \& RIVEST, 1991). No entanto, em países de clima temperado, a estação reprodutiva determina aumento na secreção das glândulas sexuais acessórias de caprinos e,

IPrograma de Pós-graduação em Ciência Veterinária, Universidade Federal Rural de Pernambuco (UFRPE). Rua Dom Manoel de Medeiros, s/n, Dois Irmãos, 52171-900, Recife, PE, Brasil. E-mail:afsfoster@gmail.com. *Autor para correspondência.

ILLaboratório de Imunopatologia Keizo Asami, Universidade Federal de Pernambuco (UFPE), Recife, PE, Brasil. 
conseqüentemente, no volume seminal, com redução na concentração espermática (LEBOEUF, 2000).

O plasma seminal proporciona boas condições para a manutenção da motilidade, da sobrevivência e do transporte espermático, tanto no sistema reprodutor do macho, quanto da fêmea (TÖPFER-PETERSEN et al., 2004). Entretanto, estudos sobre as proteínas do plasma seminal e da membrana espermática ainda precisam definir os tipos de proteínas e os mecanismos de ação que afetam a viabilidade desses gametas (ASADPOUR et al., 2007).

A composição molecular do plasma seminal possui características inerentes a cada espécie, podendo diferir entre os tipos e a atuação das proteínas espermáticas. O plasma seminal dos Bovídeos possui a família das proteínas designadas de BSP-A1/-A2 e BSP-A3 (15-17kDa), BSP-30 (28-30kDa) (MANJUNATH, 1984), e FMP, relacionadas à motilidade progressiva $(37,5 \mathrm{kDa})$. Em eqüinos, as proteínas HSP-1 (22-25kDa), HSP-2 (25kDa, pI 6,5-6,9), HSP-7 (14kDa) e HSP-12 kDa pertencem à família das espermadesinas, e a SP-1 possui correlação positiva com a fertilidade (TÖPFER-PETERSEN et al., 2004).

Em caprinos, LA FALCI et al. (2002) identificaram algumas proteínas do plasma seminal com afinidade à heparina (HAPs), cuja massa molecular é de 73 a $104 \mathrm{kDa}$ e de 119 a $178 \mathrm{kDa}$. No entanto, VILLEMURE et al. (2003) encontraram quatro bandas protéicas no plasma seminal de caprinos, denominandoas de GSP-14kDa, GSP-15kDa, GSP-20kDa e GSP-22kDa, homólogas às BSP.

O objetivo deste estudo foi identificar as proteínas presentes no plasma seminal de caprinos da raça Alpina Americana criados na região Nordeste do Brasil, colhido nos períodos de baixo (BIP) e alto (AIP) índice pluviométrico, que estão relacionadas com a qualidade dos parâmetros seminais.

\section{MATERIAL E MÉTODOS}

O experimento foi realizado no Município de Camocim de São Felix, pertencente à região Agreste do Estado de Pernambuco (microrregião do Brejo), com altitude de $650 \mathrm{~m}, 8^{\circ} 21^{\prime}, 35^{\circ} 45^{\prime}$ (Lat.S, Long.W) e clima Tropical Úmido com temperatura mínima de $10^{\circ} \mathrm{C}$ e máxima de $26^{\circ} \mathrm{C}$ e umidade entre 40 e $70 \%$. Foram utilizados três reprodutores caprinos da raça Alpina Americana, sexualmente maduros, com idade variando de 24 a 48 meses, submetidos ao regime semi-intensivo, com pastejo em capim Suázia (Digitaria swazilandensis), Tanzânia (Panicum maximum) e Braquiária (Brachiaria humidícola). Durante os dois períodos, os animais foram suplementados com $500 \mathrm{~g}$ de concentrado/dia, contendo $26 \%$ de proteína bruta e $82 \%$ de nutrientes digestíveis totais à base de milho (Zea mays ssp) triturado e farelo de soja (Glycine híspida, Maxin), além de capim Elefante (Pennisetum purpureum) no cocho. Água e sal mineral foram fornecidos ad libitum.

As colheitas de sêmen foram realizadas em duas épocas do ano classificadas de acordo com o índice pluviométrico (IP): alto IP (AIP), correspondendo aos meses de julho a agosto de 2005 (IP $=210 \mathrm{~mm}$ e temperatura média de $18,8^{\circ} \mathrm{C}$ ), e baixo IP (BIP), correspondendo ao mês de janeiro de 2006 (0mm e $22,7^{\circ} \mathrm{C}$ ), de acordo com o Laboratório de Meteorologia do Instituto Tecnológico de Pernambuco (ITEP/ LAMPE, 2007). Cada animal foi submetido a duas colheitas de sêmen consecutivas, por vagina artificial, com ajuda de uma fêmea como manequim e, em seguida, realizou-se o pool dos ejaculados, correspondendo à amostra de sêmen de cada reprodutor. Foram obtidas duas amostras de sêmen por semana, totalizando quatro amostras de cada reprodutor por período (AIP e BIP), correspondendo a 24 amostras de sêmen ao término do experimento.

Após cada colheita e formação do pool de dois ejaculados de cada animal, o sêmen foi submetido à avaliação macroscópica (cor, volume e aspecto) e microscópica (motilidade progressiva, vigor e concentração). A motilidade progressiva (MP; 0,0 $100,0 \%)$ e o vigor espermático (0-5) foram avaliados de forma subjetiva, por meio da observação em microscópio óptico (Olympus, Tókio, Japão), quando todos os ejaculados obtidos apresentavam MP e vigor mínimos de 80,0\% e 3,0, respectivamente (CBRA, 1998). A concentração espermática foi realizada pela técnica de Câmara de Neubauer, e os resultados foram expressos em bilhões de espermatozóides por ejaculado (CBRA, 1998).

Para análise de integridade de acrossoma, foram utilizadas alíquotas $(10 \mu \mathrm{L})$ das amostras de sêmen diluídas em $1,0 \mathrm{~mL}$ de solução Tris $[3,605 \mathrm{~g}$ de Tris (Sigma, Saint Louis, MO, USA), 1,488g de frutose, $2,024 \mathrm{~g}$ de ácido cítrico, $100 \mathrm{~mL}$ de água bidestilada; $\mathrm{pH}$ $6,8]$ e utilizadas para confecção de esfregaços, os quais foram armazenados a $4^{\circ} \mathrm{C}$, protegidos da luz e analisados pela técnica de coloração de fluoresceína isothiocianato-conjugada ao Peanut aglutinina (FITCPNA; Sigma, Saint Louis, MO, USA), de acordo com ROTH et al. (1998). Foram contados 200 espermatozóides/lâmina em microscópio de fluorescência (Olympus/Tókio, Japão), utilizando o filtro de fluoresceína (450-490nm, espelho dicromático de $510 \mathrm{~nm}$ ). Estes foram classificados em: a) acrossomas intactos, quando a região acrossomal apresentava 
fluorescência verde; b) acrossomas reagidos, quando apresentavam fluorescência verde na região equatorial da cabeça espermática ou não apresentavam fluorescência verde em toda cabeça da célula.

Para análise do DNA, $10 \mu \mathrm{L}$ da amostra de sêmen foram armazenadas em $990 \mu \mathrm{L}$ da solução TNE $[0,1576 \mathrm{~g}$ de TRIS- $\mathrm{HCl}(0,01 \mathrm{M}), 0,877 \mathrm{~g}$ de $\mathrm{NaCl}(0,15 \mathrm{M})$, $37,2 \mathrm{mg}$ de EDTA. $\mathrm{Na}_{2} .2 \mathrm{H}_{2} \mathrm{O}(1 \mathrm{mM})$, q.s.p. $100 \mathrm{~mL} ; \mathrm{pH}$ $7,4]$ a $-196^{\circ} \mathrm{C}$ para posterior avaliação da integridade de DNA espermático usando o corante Laranja de Acridina (Molecular Probes Inc., Eugene, OR, USA), segundo EVENSON et al. (2002). Duzentas células foram avaliadas em microscópio de fluorescência utilizando o filtro de fluoresceína $(450-490 \mathrm{~nm}$, espelho dicromático de $510 \mathrm{~nm}$ ). As células coradas de verde fluorescente foram classificadas como portadoras de DNA íntegros, enquanto aquelas que emitiram fluorescência vermelha, laranja ou amarela foram classificadas como portadoras de DNA danificado.

Para dosagem das proteínas totais pelo método de BRADFORD (1976) e eletroforese bidimensional do plasma seminal, $1,0 \mathrm{~mL}$ da amostra de sêmen foi centrifugado $(600 \mathrm{x} \mathrm{g})$ durante 10 minutos para separação dos espermatozóides do plasma seminal.

Durante a realização da eletroforese em SDS-PAGE de duas dimensões (2-D), a focalização isoelétrica (FI) foi realizada segundo BERKELMAN \& STENSTEDT (2004) em fitas Immobiline Drystrip (7cm; pH de 3,0-10,0; GE Healthcare, Chalfont St. Giles, Reino Unido), em duplicata para cada amostra analisada dos períodos de AIP e BIP. Antes da FI, as fitas foram reidratadas durante 15 horas a $28^{\circ} \mathrm{C}$, em solução tampão contendo uréia (9M; Chemical, TK, Japão), CHAPS \{3[( 3 cholamidopropil)-dimetilamonio ]- 1 propanesulfonato $\}$ a $2 \%$, Ditiotreitol (DDT) a $1 \%$, gradientes imobilizados de $\mathrm{pH}$-IPG (pH 3-10) a $2 \%$ e azul de bromofenol a $0,002 \%$, contendo $60 \mu \mathrm{g}$ de plasma seminal. Para máxima reprodutibilidade, as focalizações foram conduzidas de acordo com os seguintes parâmetros: $1 \mathrm{Vh}, 200 \mathrm{Vh}, 2.800 \mathrm{Vh}, 3.500 \mathrm{Vh}, 4.200 \mathrm{Vh}$ e $3.500 \mathrm{Vh}$ durante $3 \mathrm{~h} 30 \mathrm{~min}$ (voltagem total aplicada $\approx 8,5 \mathrm{kVh}$ ), utilizando o sistema de eletroforese Multiphor II (GE Healthcare, Chalfont St. Giles, Reino Unido). A segunda dimensão em gel de poliacrilamida a 12,5\% (2DE SDS-PAGE) (LAEMMLI, 1970) foi conduzida em corrente constante de $15 \mathrm{~mA}$ por gel, utilizando o sistema vertical (BIO-RAD). Os géis foram corados com prata. As análises dos géis 2-D foram realizadas com o programa Image MásterTM (2-D Platinum software; Amersham Biociences, England).

O experimento foi analisado em delineamento experimental inteiramente casualizado em esquema fatorial 3 x 2, com 48 repetições. Para análise dos dados, a média e o desvio padrão foram obtidos. Além disso, foram utilizados os testes estatísticos: $\mathrm{F}$ (ANOVA) para dois fatores e para um fator com comparações de Tukey, teste t-Student com variâncias iguais ou desiguais, teste de Mann-Whitney e teste de Kruskal-Wallis (Técnicas de estatística inferencial). A verificação da hipótese de igualdade de variâncias foi realizada pelo teste $\mathrm{F}$ de Levene. Foi utilizado o nível de significância de 5\%. Os dados foram processados e analisados pelo programa SPSS (Statistical Package for the Social Sciences) na versão 13.

\section{RESULTADO E DISCUSSÃO}

$\mathrm{O}$ volume seminal dos três reprodutores no período $\operatorname{AIP}(2,1 ; 1,2 \mathrm{e} 1,8 \mathrm{~mL}$, respectivamente) foi maior $(\mathrm{P}<0,05)$ do que no $\operatorname{BIP}(1,2 ; 0,9$ e $1,4 \mathrm{~mL}$, respectivamente) está descrito na figura 1-I. Esse resultado pode ser explicado pelo fato de maior disponibilidade de forragem verde e menor ocorrência de temperaturas elevadas no período chuvoso (AIP) ter determinado melhoria geral das condições corporais dos animais e maior volume seminal, o que corrobora com os resultados de NUNES (1988), ao relatar que na época de chuvas o sêmen de caprinos da raça AngloNubiana apresenta melhores parâmetros quantiqualitativos do que no período de seca, provavelmente devido à maior temperatura no período seco. A redução do volume seminal indica menos secreção das glândulas acessórias, determinando ausência ou diminuição de alguns constituintes, como proteínas do plasma seminal (SANTOS \& SIMPLÍCIO, 2000).

Concentração, motilidade progressiva e vigor espermático não apresentaram diferença significativa $(\mathrm{P}>0,05)$ entre reprodutores e entre os períodos AIP $\left(2,3 \times 10^{9} \mathrm{~mL}^{-1}, 79,8 \%, 4,2\right)$ e BIP $(2,3 \times$ $10^{9} \mathrm{~mL}^{-1}, 81,3 \%, 4,0$ ), respectivamente (Figura 1 - II, III e IV). Esses dados corroboram parcialmente com os resultados de SILVA et al. (2005), ao relatarem que os caprinos mestiços F1 (Anglo-Nubiana x SRD) encontram-se bem adaptados às condições climáticas do Semi-Árido paraibano, não apresentando alteração na motilidade e no vigor espermático durante $o$ ano. Todavia, segundo esses autores, a concentração espermática apresentou-se reduzida no período mais quente do ano, diferindo dos resultados obtidos neste estudo.

A dosagem das proteínas totais apresentou maior concentração $(\mathrm{P}<0,05)$ no período $\operatorname{AIP}(147,9 \mu \mathrm{g}$ $\left.\mathrm{mL}^{-1}\right)$ do que no BIP $\left(103,8 \mu \mathrm{g} \mathrm{mL}^{-1}\right)$ de acordo com a figura 1 - IV, corroborando com outros estudos que evidenciam influência da estação do ano na composição do plasma seminal e nos índices de proteínas do sêmen 


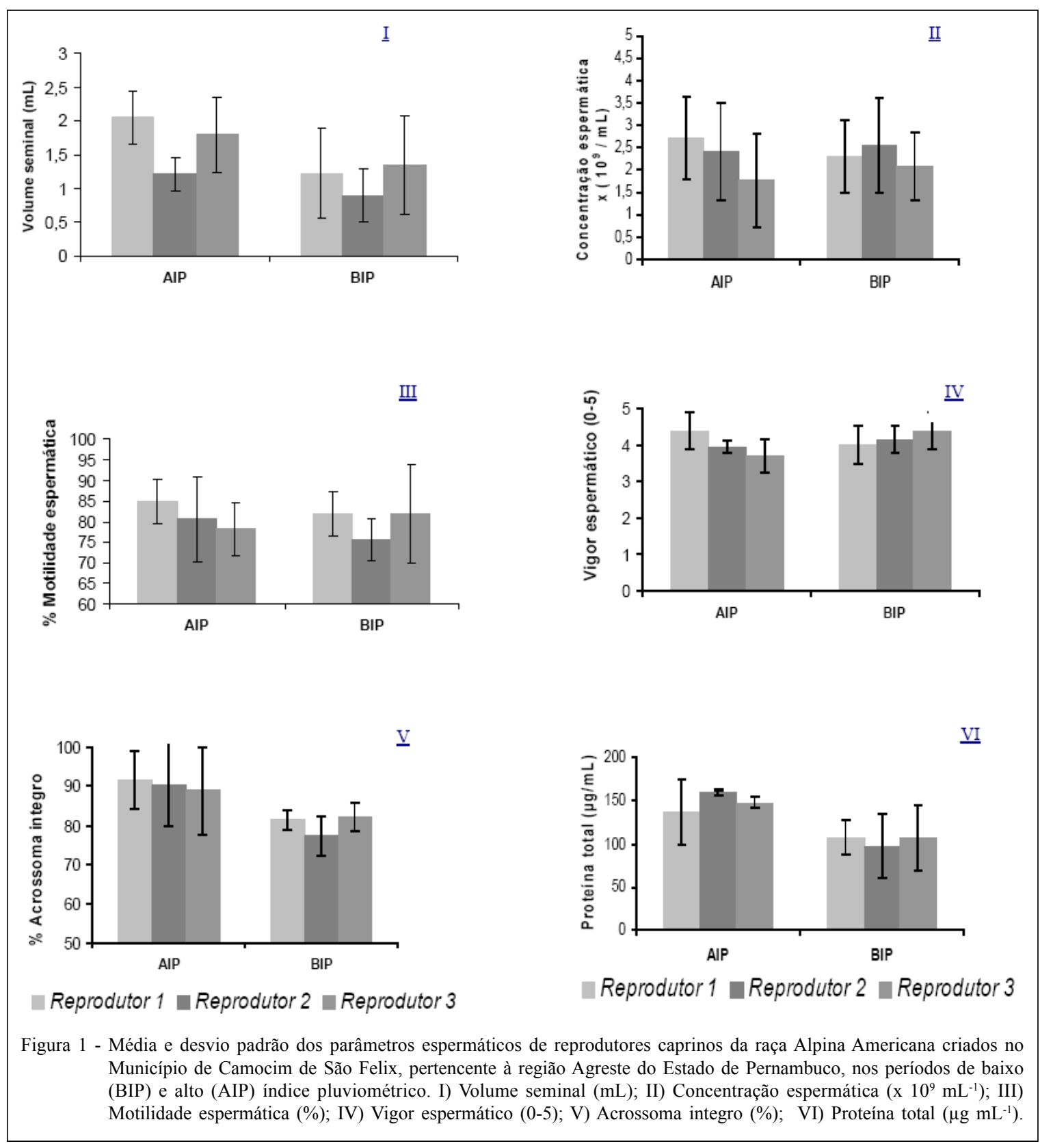

ovino (SMITH et al., 1999), do caprino (La FALCI et al., 2002) e do bovino (RONCOLETTA et al., 1999). A análise do perfil das proteínas do plasma seminal realizada com SDS-PAGE bidimensional nos períodos AIP e BIP detectou 96 spots de proteínas, sendo 47 spots com massa molecular relativa de 4 a $106 \mathrm{kDa}$ e pI de 3,00 a 8,96 no período AIP e 49 spots no período BIP, apresentando massa molecular relativa de 15 a $97 \mathrm{kDa}$, com pI de 4,48 a 9,83. A maior diversidade de proteínas obtidas por meio da técnica de eletroforese foi encontrada no período BIP (49 spots), quando foi verificada ausência de proteínas de baixa massa molecular $(<15 \mathrm{kDa})$, as quais, segundo JOBIM et al. (2003), encontram-se envolvidas na manutenção da motilidade espermática.

No período AIP, $76,6 \%$ dos spots de proteínas apresentaram pontos isoelétricos na faixa de pH ácido (3,0 a 6,8) e 23,4\% em pH básico (7,1 a 9,1). Da mesma forma, no período BIP, $77,6 \%$ dos spots encontravam-se na faixa de pH ácido (4,6 a 6,9) e 22,5\% de $\mathrm{pH}$ básico $(7,6$ a 9,6). Ao serem comparados os períodos AIP e BIP, foi verificada a presença de 22 spots de proteínas comuns, com $45,8 \%$ de similaridade entre as massas moleculares relativas dessas proteínas, 
sendo 15 spots de proteínas entre 40 e $106 \mathrm{kDa}$, correspondendo a $68,2 \%$ dos spots de proteínas similares e sete spots de proteínas com massas moleculares relativas entre 10 e $39 \mathrm{kDa}$, correspondendo a $31,8 \%$ das proteínas similares.

Vários componentes do plasma seminal estimulam o metabolismo dos espermatozóides, atuando na manutenção da motilidade e na proteção espermática pela redução de peróxidos, como as proteínas ácidas do fluido seminal (aSFP; $13 \mathrm{kDa})$ e a enzima desidrogenasse láctica C4 (SILVA et al., 2003). Neste estudo, um grupo de proteínas de $13 \mathrm{kDa}$ (pI 8,96 a 5,73) foi identificado nas amostras do período AIP, sendo observados $90,3 \%$ de espermatozóides com acrossomas íntegros, sugerindo que essas proteínas auxiliam na preservação da integridade das membranas espermáticas (SILVA et al., 2003). Apenas no período AIP foram focalizadas proteínas com massa molecular relativa inferior a $15 \mathrm{kDa}$, correspondendo a 22 spots de proteínas $(46,8 \%)$ encontrados no gel de eletroforese.

Nos bovinos, as aSFP $(15-16 \mathrm{kDa}$ e $\mathrm{pI}$ de $4,7-5,2 ; 11-12 \mathrm{kDa}$ e pI de 4,8-4,9; 13-14kDa e pI de 6,06,$5 ; 18-20 \mathrm{kDa}$ e $\mathrm{pI}$ de $4,8-5,2$ ) atuam como antioxidante na prevenção da peroxidação lipídica da membrana espermática, contrapondo o efeito deletério da elevada produção e liberação de peróxido das membranas de células mortas, com o objetivo de preservar a viabilidade dos espermatozóides vivos (JOBIM et al., 2003). Neste estudo, os resultados das análises das imagens dos géis pelo programa Image Máster apresentaram 10 spots de proteínas com menos de $18 \mathrm{kDa}$, tanto no AIP (13kDa, pI 5,73-6,30; 12kDa, pI 9,14; 11kDa, pI 7,55; 10kDa, pI $7,73)$, quanto no BIP (17kDa, pI 6,08-6,44; 16kDa, pI 9,07;15kDa, pI 7,58-7,59).

Em bovinos, algumas proteínas atuam na indução da motilidade progressiva, juntamente com o cAMP, tais como quatro a cinco proteínas com $37,5 \mathrm{kDa}$ (SHIVAJI et al., 1990) e proteínas BSP-A1/-A2 e BSP$\mathrm{A} 3$, com massas moleculares relativas de $15-17 \mathrm{kDa}$ e $30 \mathrm{kDa}$, respectivamente, e BSP-30, com massa molecular do 28-30kDa (MANJUNATH, 1984). Em caprinos essas proteínas estão presentes nas amostras de sêmen in natura e são denominadas de proteína seminal caprina (GSP; $14-15 \mathrm{kDa}$ ). Segundo CARDOZO et al. (2006), essas proteínas estão relacionadas com a família das BSP e se ligam à membrana espermática durante o trânsito epididimário, atuando na capacitação espermática (VILLEMURE et al., 2003). Neste estudo, o grupo de proteínas com 14-15kDa esteve presente no plasma seminal em ambos os períodos avaliados (AIP e BIP), juntamente com outro grupo de proteínas com massas moleculares de 38-39kDa e pI de 5,21-5,42, onde foram observados valores de motilidade progressiva iguais a 81,3 e $79,8 \%$, respectivamente, corroborando as afirmações de VILLEMURE et al. (2003) e CARDOZO et al. (2006).

Em búfalos, ASADPOUR et al. (2007) afirmaram que o surgimento de uma proteína de $45 \mathrm{kDa}$ no plasma seminal é responsável pelo maior número de células espermáticas danificadas pós-descongelação. Neste estudo, uma proteína com massa molecular relativa de $45 \mathrm{kDa}$ e pI 5,5 também foi identificada nas amostras de sêmen colhidas no período AIP. No entanto, as análises evidenciaram, neste período, maior porcentual $(\mathrm{P}<0,05)$ de células com acrossomas íntegros (90,3\%), em comparação com o BIP $(80,3 \%)$, onde não foi identificada a presença desta proteína (Figura 1 V). A perda da integridade da membrana espermática é um fator que contribui para o declínio da motilidade (ALMEIDA, 2006). No entanto, neste estudo foi observado maior porcentual $(\mathrm{P}<0,05)$ de células com acrossomas íntegros no período AIP, mas não se constatou diferença significativa $(\mathrm{P}>0,05)$ na motilidade progressiva nos períodos AIP e BIP, quando todos os ejaculados obtidos dos animais apresentavam valores de MP maior que 70,0\%, considerados mínimos aceitáveis para um caprino reprodutor com potencial satisfatório (PUGH et al., 2006). Assim, sugere-se que esta proteína ( $45 \mathrm{kDa}$ e $\mathrm{pI}$ de 5,5$)$ no plasma seminal de caprinos possui a função apenas de proteger a célula espermática de danos no acrossoma.

Determinadas proteínas do plasma seminal se aderem aos espermatozóides no trânsito epididimário ou durante a ejaculação, podendo retardar a capacitação e, conseqüentemente, a reação acrossômica (MANJUNATH \& THÉRIEN, 2002). Essas proteínas são denominadas de decapacitantes e são removidas ou modificadas pelos fluidos do sistema reprodutor feminino durante a capacitação espermática e a fecundação (FRAZER et al., 1996). As caltrinas, denominação dada às proteínas decapacitantes, são proteínas do plasma seminal que possuem baixa massa molecular ( 5 a $10 \mathrm{kDa}$ ) e previnem o aumento da concentração de $\mathrm{Ca}^{2+}$ nos espermatozóides, evitando a capacitação espermática precoce provocada pelo processo de criopreservação (FLESCH \& GADELLA, 2000). Neste estudo, proteínas com massas moleculares relativas de 4 a $10 \mathrm{kDa}$ foram identificadas no período AIP, quando foi observado maior porcentual de células vivas com acrossomas íntegros.

Nas amostras do plasma seminal de caprinos colhidas nos períodos AIP e BIP, submetidas à eletroforese bidimensional, foram focalizadas proteínas com massas moleculares entre 78 e 106kDa (AIP) e 74 a $97 \mathrm{kDa}(\mathrm{BIP})$. Essas proteínas também foram denominadas por La FALCI et al. (2002) como proteínas 
com afinidade à heparina (HAPs), com massa molecular de 73 a $104 \mathrm{kDa}$ e 119 a $178 \mathrm{kDa}$, cuja presença pode ser responsável pela redução da motilidade espermática e da integridade do acrossoma. Os resultados deste estudo não corroboram com La FALCI et al. (2002), em virtude de a motilidade progressiva não ter demonstrado diferença significativa $(\mathrm{P}>0,05)$ entre períodos (AIP e BIP), enquanto o porcentual de espermatozóides com acrossomas íntegros foi maior $(\mathrm{P}<0,05)$ no período AIP do que no BIP, apesar desses parâmetros (motilidade e acrossomas íntegros) estarem dentro dos padrões estabelecidos para o sêmen caprino. Ressalta-se ainda que a análise do porcentual de espermatozóides com DNA íntegros nos períodos AIP e BIP demonstrou que os valores foram iguais ou próximos a $100,0 \%$, sem evidenciar diferença $(\mathrm{P}>0,05)$ entre reprodutores, períodos ou interação reprodutor $\mathrm{X}$ período.

Com base nos resultados de volume seminal, porcentual de espermatozóides com acrossomas íntegros, assim como proteínas totais e perfil protéico do plasma seminal, é possível concluir que o sêmen de caprinos da raça Alpina Americana criados na região Nordeste do Brasil apresenta-se com melhor qualidade quando colhido no período de alto índice pluviométrico, o que pode ser atribuído à presença das proteínas de $13 \mathrm{kDa}$ e $45 \mathrm{kDa}$.

\section{AGRADECIMENTOS}

Ao proprietário do Sítio da Aratanha, por ceder os animais para este experimento; ao Laboratório de Imunopatologia Keizo Asami (LIKA/UFPE), pela oportunidade de realização das dosagens de proteínas; à Fundação de Amparo à Ciência e Tecnologia do Estado de Pernambuco (FACEPE), pela concessão de auxílio financeiro e à Coordenação de Aperfeiçoamento de Pessoal de Nível Superior (CAPES), pela concessão de bolsa de doutorado.

\section{REFERÊNCIAS}

ALMEIDA, J.L. Efeito de diferentes concentrações de plasma seminal na criopreservação do sêmen eqüino. 2006. 77f. Dissertação (Mestrado em Ciências agrárias) Universidade de Brasília/Faculdade de Agronomia e Medicina Veterinária, Brasília.

ASADPOUR, S.M. et al. SDS-polyacrylamide gel electrophoresis of buffalo bulls seminal plasma proteins and their relation with semen freezability. Animal Reproduction Science, v.102, p.308-313, 2007. Disponível em: http://www.sciencedirect.com/ science?_ob=ArticleURL\&_udi=B6T43-4N6FFRP$3 \&$ user $=687358 \&$ rdoc $=1 \&$ fmt $=\&$ orig $=$ search \&_so

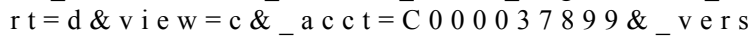
i o $n=1 \&$ u r $1 \overline{\mathrm{V}}$ e r s i o $n=0 \& \&_{\text {u s e r } \overline{\mathrm{i}} \mathrm{d}=6}$ $87358 \&$ md5 $=67$ fa 5 dc 4 deb19a19d022e 4 f69 $\mathrm{ff} 5 \mathrm{fb} 9 \mathrm{~d}$. Doi: 10.1016/j.anireprosci.2007.03.003.
BERKELMAN, T., STENSTEDT, T. 2D electrophoresis: principles and methods. Uppsala: Amersham Pharmacia Biotechenology, 2004. 162p.

BRADFORD, M.M. A rapid and sensitive method for the quantification of microgram quantities of protein utilizing the principles of protein-dye binding. Analytical Biochemistry, v.72, p.248-254, 1976.

CARDOZO, J.A. et al. Monthly variations in ovine seminal plasma proteins analyzed by two dimensional polyacrylamide gel electrophoresis. Theriogenology, v.66, n.4, p.841-850, 2006. Disponível em: http://www.sciencedirect.com/ science?_ob=ArticleURL\&_udi=B6TCM-4JFHDVT$2 \& \_$user $=687358 \&$ rdoc $=1 \&$ fmt $=$ \&_orig $=$ search \&_sort $=\mathrm{d} \& \mathrm{~V}$ $\mathrm{iew}=\mathrm{c} \&$ \& a c t $=\overline{\mathrm{C}} 000037899 \&$ \&_version $=1 \&$ \& urlV ersion $=0 \&$ userid $=687358 \& \mathrm{md} 5=7 \mathrm{dc} 4 \mathrm{f} 7721 \mathrm{~b} 855 \mathrm{~d} 0 \mathrm{e} 0 \mathrm{da} 8 \mathrm{aaa} 0 \mathrm{~d} 1108 \mathrm{bec}$. Doi: $10 . \overline{1016 / j . t h e r i o g e n o l o g y .2006 .01 .058 . ~}$

CBRA. Manual para exame andrológico e avaliação do sêmen animal. 2.ed. Belo Horizonte, 1998. 49p.

EVENSON, D.P. et al. Sperm chromatin structure assay: Its clinical use for detecting sperm DNA fragmentation in male infertility and comparisons with other techniques. Journal of Andrology, v.23, n.1, p.25-43, 2002.

FLESCH, F.M.; GADELLA, B.M. Dynamics of the mammalian sperm plasma membrane in process of fertilization. Biochimica et biophysica acta, v.1469, p.197-235, 2000. Disponível em: http:// www.sciencedirect.com/science?_ob=ArticleURL\&_udi=B6T22$41 \mathrm{~J} 60 \mathrm{H} 2-4 \&$ user $=687358 \&$ rdoc $=1 \&$ fmt $=\&$ _orig $=$ search\&_sort $=\mathrm{d}$ 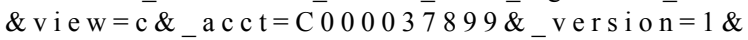 u r l V e r s i o n $=0 \&$ u s e r i $\bar{d}=687358$ \&md5=75be9620af8c9a6d0222979905b8dd57. Doi: 10.1016/S03044157(00)00018-6.

FRAZER, G.S. et al. Two-dimensional polyacrylamide gel electrophoresis of bovine semen after cryopreservation in halfmillilitre straws. Theriogenology, v.46, p.1103-1115, 1996.

JOBIM, M.I.M. et al. Proteínas de baixo peso molecular do plasma seminal bovino relacionadas com a congelabilidade do sêmen através de eletroforese bidimensional em gel de poliacrilamida. Acta Scientiae Veterinariae, v.31, n.1, p.2130,2003 .

La FALCI, V.S.N. et al. Seasonal variation of goat seminal plasma proteins. Theriogenology, v.57, p.1035-1048, 2002. Disponível em: $\mathrm{http}: / /$ www.sciencedirect.com/science?_ob=ArticleURL\&_udi=B6TCM44 YF8PM-2\& user $=687358 \&$ rdoc $=1 \&$ fmt $=\&$ orig $=$ search $\&$ s ort $=$ d\& view $=$ c\&_acct $=$ C $000037899 \&$ \&version $=1 \&$ u r l Versio $n=0 \&$ u s e ri d $=687358 \& \mathrm{~m} \mathrm{~d} 5$ $=\mathrm{d} 065 \mathrm{c} 7 \mathrm{~b} 4 \mathrm{~d} 8 \mathrm{c} 18 \mathrm{~b} 4 \mathrm{cbabf} 8 \mathrm{f} 2 \mathrm{c} 4 \mathrm{fd} 912 \mathrm{f} 3$. Doi: $10.1016 / \mathrm{S} 0093-$ 691X(01)00714-2.

LAEMMLI, U.K. Cleavage of structural proteins during the assembly of the head of bacteriophage T4. Nature, London, v.277, p.680-685, 1970. Disponível em: http://www.nature.com/ nature/journal/v227/n5259/abs/227680a0.html. Doi: 10.1038/ $227680 \mathrm{a} 0$.

LEBOEUF, B. et al. Production and storage of goat semen for artificial insemination. Animal Reproduction Science, v.62, p.113-141, 2000. Disponível em: http://www.sciencedirect.com/ 
science?_ob=ArticleURL\&_udi=B6T43-40TXY4W-

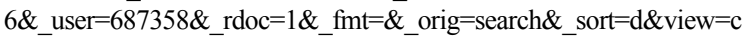
\&_acct $=$ C $000037899 \&$ \& version $=1 \&$ \& urlVersion 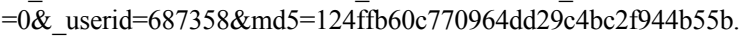 Doi: 10.1016/S0378-4320(00)00156-1.

MANJUNATH, P. Gonadotropin release stimulatory and inhibitory proteins in Bull seminal plasma. In: SAIRAM, M.R.; ATKINSON, L.E. (Eds.) Gonadal proteins and peptides and their biological significance. Singapore: World Scientific, 1984. p.49-61.

MANJUNATH, P.; THÉRIEN, I. Role of seminal plasma phospholipidbinding proteins in sperm membrane lipid modification that occurs during capacitation. Journal of Reproductive Immunology, v.53, p.109-119, 2002.

NUNES, J.F. Fatores que influenciam os aspectos quantiqualitativos do sêmen de caprinos no Nordeste do Brasil. Revista Brasileira Reprodução Animal, v.12, n.2, p.77-83, 1988.

PUGH, D.G. Clínica de ovinos e caprinos. São Paulo: Roca, 2005. 513p.

RIVER, C.; RIVEST, S. Effect of stress of the activity of the hypothalamic-pituitary gonadal axis: peripheral and central mechanisms. Biology of Reproduction, v.45, p.523-532, 1991.

RONCOLETTA, M. et al. Perfil em SDS-PAGE das proteínas do plasma seminal, e sua relação com a congelabilidade do sêmen de touros doadores da raça GIR. Brazilian Journal of Veterinary Research and Animal Science, v.36, n.2, 1999.

ROTH, T.L. et al. Heterologous in vitro fertilization and sperm capacitation in an endangered African antelope, the Scimiltar Horned Oryx (Oryx dammah). Biology of Reproduction, v.58, p.475-482, 1998.
SANTOS, D.O.; SIMPLÍCIO, A.A. Parâmetros escrototesticulares e de sêmen em caprinos adultos submetidos à insulação escrotal. Pesquisa Agropecuária Brasileira, v.35, n.9, p.1835-1841, 2000. Disponível em: http://www.scielo.br/ s c i e lo.php ? s c ri pt $=$ s ci_art text \& pid $=$ S $0100-$ 204X2000000900016\&lng=en\&nrm=iso\&tlng=pt. Doi: $10.1590 /$ S0100-204X2000000900016.

SHIVAJI, S. et al. Proteins of seminal plasma. New York: John Wiley and Sons, 1990. 526p.

SILVA, A.E.D.F. et al. Conteúdo de peptídeos e avaliação morfofisiológica dos espermatozóides do epidídimo e ejaculado de bovinos. Revista Brasileira de Zootecnia, v.32, n.6, p.1890-1900, 2003.

SILVA, G.A. et al. Efeito das épocas do ano e de turno sobre os parâmetros físiológicos e seminais de caprinos no semi-árido paraibano. Agropecuária Científica no Semi-árido, v.1, p.7-14, 2005.

SMITH, J.F. et al. Seasonal changes in the protein content and composition of ram seminal plasma. Proceedings of the New Zealand Society of Animal Production, v.59, p.223225, 1999

TÖPFER-PETERSEN, E. et al. The role of stallion seminal proteins in fertilization. Animal Reproduction Science, v.89, n.14, p.159-170, 2004. Disponível em: http://www.sciencedirect.com/ science? ob=ArticleURL\& udi=B6T43-4GY891R$1 \&$ _user $=687358 \&$ _rdoc $=1 \&$ fmt $=\&$ _orig $=$ search $\&$ _sort $=\mathrm{d} \&$ vie $\mathrm{w}=\mathrm{c} \&$ acct $=\mathrm{C} 000037899 \&$ version $=1 \&$ urlVersion $=0 \&$ _userid $=687358 \& \mathrm{md} 5=301590 \mathrm{~b} 3 \mathrm{f} 18 \mathrm{f} 92 \mathrm{bdcfe} 498384 \mathrm{~b} 99 \mathrm{dacf}$. Doi: $10.1016 /$ j.anireprosci.2005.06.018.

VILLEMURE, M. et al. Isolation and characterization of gelatine-binding proteins from goat seminal plasma. Reproductive Biology and Endocrinology, v.1, p.39, 2003. 